Flávio Glória Caminada Sabrá

Os agentes sociais envolvidos no processo criativo no desenvolvimento de produtos da Cadeia Têxtil

Tese de Doutorado

Tese apresentada ao Programa de PósGraduação em Design do Departamento de Artes \& Design do Centro de Teologia e Ciências Humanas da Pontifícia Universidade Católica do Rio de Janeiro como requisito parcial para obtenção do título de Doutor em Design.

Orientador: Prof. Alberto Cipiniuk 
Flávio Glória Caminada Sabrá

\section{Os agentes sociais envolvidos no processo criativo no desenvolvimento de produtos da Cadeia Têxtil}

Tese apresentada ao Programa de Pós-Graduação em Design da PUC-Rio como requisito parcial para obtenção do grau de Doutor em Design. Aprovada pela Comissão Examinadora abaixo assinada.

Prof. Alberto Cipiniuk

Orientador

Departamento de Artes \& Design - PUC-Rio

Profa. Vera Lúcia Moreira dos Santos Nojima

Departamento de Artes \& Design - PUC-Rio

Profa. Fernanda de Abreu Cardoso Universidade Federal do Rio de Janeiro - UFRJ

Profa. Luciana Montenegro da Silva Pereira Centro de Tecnologia da Indústria Química e Têxtil - CETIQT

Profa. Kathia Castilho Cunha

Associação Brasileira de Estudos e Pesquisas em Moda - ABEPEM

Profa. Denise Berruezo Portinari Coordenadora Setorial do Centro de Teologia e Ciências Humanas - PUC-Rio 
Todos os direitos reservados. É proibida a reprodução total ou parcial do trabalho sem autorização da universidade, do autor e do orientador.

Flávio Glória Caminada Sabrá

Mestre em Administração (IBMEC-RJ), Especialista em $1^{\mathrm{a}}$ Gerência em Marketing (ESPM-RJ), Especializando em Gerenciamento de Projetos (FGVRJ), Graduado em Desenho Industrial pela Faculdades Integradas Silva e Souza (FISS-RJ) e Técnico de Estilismo em Confecção Industrial (SENAI CETIQT$\mathrm{RJ})$. Designer, professor, pesquisador e gestor com interesse nos processos de criação e produção vinculados aos diferentes agentes da cadeia têxtil.

Ficha Catalográfica

Sabrá, Flávio Glória Caminada

Os agentes sociais envolvidos no processo criativo no desenvolvimento de produtos da Cadeia Têxtil / Flávio Glória Caminada Sabrá ; orientador: Alberto Cipiniuk. - 2015.

143 f. : il. (color.) ; $30 \mathrm{~cm}$

Tese (doutorado)-Pontifícia Universidade Católica do Rio de Janeiro, Departamento de Artes \& Design, 2015. 


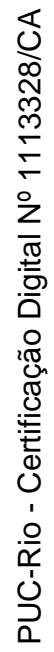

Para os meus amados pais Miguel e Ester.

Para os meus amores Bilu e Joaquim. 


\section{Agradecimentos}

Aos meus amados pais Miguel e Ester por terem me ensinado a respeitar a tudo e a todos, amar a vida acima de tudo e sempre buscar a harmonia entre o pensar, o fazer e o entregar, mesmo que seja em uma nova empreitada. Agradeço a oportunidade de terem me dado à mão quando decidi atuar como um agente da cadeia de Moda.

Ao meu grande amor e companheira Deborah, que virou Bilu, Biluzinha, que virou Centopeia, que virou Amore e que está sempre ao meu lado como amante, esposa, agente, entre outros significados, que juntos construímos o nosso melhor produto, Joaquim. Joaquim que une, que ri, que questiona, que ama, que chora, que aprende, que ensina. Joaquim o nosso querido e amado filho.

Aos meus irmãos Valéria, Fernando, Vanessa e Camila, que me fazem amar e ser amado e que juntos aprendemos com os nossos pais que viver a vida é a melhor oportunidade que temos. Juntos, estamos construindo as nossas próprias famílias e juntos também estamos tendo a oportunidade de mudar muitas outras famílias.

Com os meus irmãos vieram as minhas novas famílias, Alexandre, Natália, Vitória e Luiza, Marilene, Anna Clara e João Miguel, Renato e ..., Felipe, Margot, Frida e ... e muitos outros que estão por vir.

A vovó Edna, aquela que acolhe, que acalma, que cuida e que ama.

Ao Professor Alberto Cipiniuk, pela arte de ensinar e estar comigo nesta caminhada.

As Professoras avaliadoras da banca, Vera, Denise, Luciana, Kathia, Rita e Fernanda, que mesmo antes de ler os textos, me receberam com profissionalismo e carinho. 
A minha grande e nova amiga Anna, obrigado pelas leituras, correções e diálogos, afinal constituímos uma nova família.

Aos meus amados compadres Cris, Dede, João e Benício, Aldinho e Dinda.

Aos meus amigos de muitos anos, agentes da Cadeia Têxtil: Luisa Meirelles e Gaúcho, Guido, Iza e Waltinho, Paulo Fulco, Rosa Marly, Valéria Delgado, Paulinho d`Escragnolli, Rosa Basin, Cláudia Pepe e Pepe, Lu Monte, Kathia Castilho, Leo Mendes, Ariel, Marcinha, Zump, Leo Magalhães, Aninha e Guto, Carlinha, Selma, Sérgio Bastos, Flavio Bruno, Rynaldo Rosa, Camila Lamarão, Luiz Felipe, Evelyne, Simas, Kátia Pires, Pat Dinis, Michelle, Chris Rangel, Angel, Priscila, Joana, Fernanda, Cecília, Pat Mattos, Luciene, Paulinho, Pedro Toste, Tadea, Naccarato, Rosane Kalil, Vânia Polly, Caê, Leila Lemgruber, Mônica Queiroz, Paulo Leite, Daniel, Du Carmo, Rogério Santinni, Eliete, Babi Poci, Flávia Duta, Gláucia Regina, Dalva, Heloisa Helena, João Dalla, Sérgio Sudsy, Maya Estarque, Helô Belo, Geysa, Sônia Volpini, Elna Cipriano, Alan Kardec, Dedezinho, Luiz Cláudio, Sheila Leitão, Verônica Black, Beto Neves, Titi Seixas, Lu Catoira, Ildeth, Thereza Imbiriba, Cris Diogo, Dani Brum, Lala, Iria, Júlia, Gaspar, Felisberto, Lizander, Lívia, Dani Joia, Paloma, Ney, entre muitos professores amigos e amigos professores.

Aos meus amigos de sempre, Gerson, Ilze, Davi e Rebeca, Marcus, Cristina, Gabriela e Júlia.

Aos meus amigos da Rede SENAI de Tecnologia Têxtil e de Confecção.

As empresas em que atuei como um agente da Cadeia Têxtil.

Aos meus professores de ontem, hoje e amanhã, afinal ser aluno e estar em sala de aula como aluno é fantástico.

Aos meus alunos de ontem, hoje e amanhã, afinal estar em sala de aula é uma das muitas descobertas da minha vida como agente da Cadeia Têxtil e de Confecção que foi, é e será sempre uma fantástica fábrica de surpresas.

..... afinal o mundo é redondo !!! 


\section{Resumo}

Sabrá, Flávio Glória Caminada; Cipiniuk, Alberto (orientador). Os agentes sociais envolvidos no processo criativo no desenvolvimento de produtos da Cadeia Têxtil. Rio de Janeiro, 2015. 143 p. Tese de Doutorado Departamento de Artes \& Design, Pontifícia Universidade Católica do Rio de Janeiro.

As reflexões desenvolvidas neste trabalho têm por finalidade discutir o papel dos agentes que atuam na cadeia têxtil e, consequentemente, o papel do designer como um dos que proporcionam os meios para o entendimento da dialética entre o que chamamos de processo criativo e as demandas do mercado. Um artefato produzido pela cadeia têxtil está diretamente ligado a todos nós no dia a dia, seja como usuários diretos, seja como indiretos. Ocorre que seu processo de desenvolvimento é complexo, e muitas vezes desconhecido por aqueles que nele estão envolvidos - tanto os que atuam como legitimadores quanto os seus usuários. A atuação do designer normalmente é vinculada apenas ao processo criativo, mesmo quando levado em consideração o fato de que seu trabalho depende de informações provenientes de uma estrutura mais ampla e complexa, que envolve a necessidade de conhecimento sobre materiais, processos de fabricação e distribuição, e processos de uso e de consumo. Entretanto, o entendimento de que a estrutura dessa cadeia produtiva é mais complexa, composta por diferentes agentes sociais, leva a pensar que o designer é somente mais um profissional, cuja prática influencia, mas também é influenciada por tantos outros agentes sociais pertencentes ao campo; desta forma, o processo criativo se revela uma atividade coletiva que envolve vários agentes. Criar um produto de moda, aqui descrito como um objeto inserido na cadeia têxtil é muito mais complexo do que o simples desenvolvimento daquele artefato que nos é apresentado como temporal no desfile de uma específica coleção de moda. Propõe-se, então, aqui apresentar o modo pelo qual se estabelece a relação, direta 
ou indireta, com todos aqueles envolvidos na cadeia têxtil, para identificar como essas relações interferem no processo criativo, tradicionalmente associado apenas à intencionalidade e aos méritos do designer.

\section{Palavras-chave}

Design; Moda; Vestuário; Cadeia Produtiva Têxtil. 


\section{Abstract}

Sabrá, Flávio Glória Caminada; Cipiniuk, Alberto (Advisor). The social agents involved in the creative process in product development of Textile Chain. Rio de Janeiro, 2015. 143 p. PhD Thesis - Departamento de Artes \& Design, Pontifícia Universidade Católica do Rio de Janeiro.

Reflections developed in this work are intended to discuss the necessity of the role of agents working in the textile chain and hence the designer as one of providing ways for understanding that what we call creative process, as well as market demands and its dialectic with the whole process. An artifact produced by the textile chain is directly linked to all of us in everyday life, either as direct or indirect users. It turns out that its development process is complex and, often, unknown by those involved as well as those who act as legitimators, plus those who are its members. The acting of the designer is usually linked only to the creative process, even when we take into consideration that your job depends on information from a broader and more complex structure that involves the need for knowledge of materials, manufacturing processes and distribution and use processes and consumption. However understand that the structure of this supply chain is more complex and consists of different actors, makes us think that he is just another professional whose practice influences, but is also influenced by many other social agents belonging to the field, and with it often we do not realize that the creative process is a collective activity involving these various agents. Create a fashion product, described here as an object that is inserted in the textile chain is much more complex than the simple development of that artifact that is presented to us as temporal at a fashion show in a specific fashion collection. We propose as assessed within the relationship, direct or indirect, with all those involved in the textile chain to identify how these relationships interfere with the creative process, 
traditionally associated only intentionality and merits of the designer.

\section{Keywords}

Design; Fashion; Apparel; Textile Productive Chain. 


\section{Sumário}

1. Introdução 13

2. O processo criativo como atividade coletiva

4. O desenvolvimento de produtos dentro da Cadeia Têxtil

4.1 Relações de consumo no desenvolvimento de produtos têxteis

4.2. O papel do designer dentro do desenvolvimento de produtos têxteis

4.3. A obsolescência programada e a moda influenciando o desenvolvimento de produtos têxteis

4.5. Os agentes sociais e fatores que interferem no processo criativo do desenvolvimento de produtos têxteis

5. Conclusão 


\section{Lista de Tabelas}

Tabela 1 - Fluxo de produção da Cadeia Têxtil 